\title{
DO MULTICULTURALISMO AO INTERCULTURALISMO. UM NOVO MODO DE INCORPORAÇÃO DA DIVERSIDADE CULTURAL?
}

\section{FROM MULTICULTURALISM TO INTERCULTURALISM. A NEW MODE OF INCORPORATION OF CULTURAL DIVERSITY?}

\author{
Nuno Oliveira ${ }^{1}$
}

\section{RESUMO}

Neste texto pretendemos discutir o interculturalismo como novo modelo de acomodação da diversidade cultural. Defendemos que este é um paradigma concorrente ao multiculturalismo e que a discussão não deve ficar apenas pelos aspectos teóricos e normativos, mas antes integrar criticamente as formas práticas com que o interculturalismo organiza a diferença social. Argumentamos que tais formas configuram um modelo delineado segundo três vetores. Primeiro, a europeização, ou seja, a disseminação dos mesmos scripts pelas instituições imprimindo modos de fazer idênticos e uniformizadores. Segundo, o redimensionamento da escala do espaço de integração dos imigrantes do nacional para o local. Terceiro, o seu ajustamento às novas lógicas de governança urbana. Tais transformações produzem novas formas de visibilização para aquilo que surge como uma aceitação generalizada da pluralidade das pertenças no seio de um imaginário social presidido pela ideia de diversidade. Este é construído segundo um figurino específico que procuramos caracterizar neste texto, onde ressaltam as novas lógicas de desenvolvimento urbano, do papel da cultura e da centralidade do espaço local.

Palavras-chave: Interculturalismo. Multiculturalismo. Europeização. Governança Urbana. Reconhecimento.

\footnotetext{
${ }^{1}$ Doutor em Sociologia. Investigador de pós-doutoramento no Centro de Investigação e Estudos de Sociologia no Instituto Universitário de Lisboa (CIES-ISCTE). E-mail: filicastrol@gmail.com.
} 


\begin{abstract}
In this text we intend to discuss interculturalism as a new model for the accommodation of cultural diversity. We argue that this is a paradigm competing with multiculturalism and that the discussion should not only be based on theoretical and normative aspects, but rather must critically integrate the practical forms with which interculturalism organizes social difference. We argue that such forms constitute a model which outline is threefold. First, the Europeanization of the model, that is, the dissemination of the same scripts by the institutions imprinting identical and uniform ways of doing. Second, the rescaling of migrants' space of integration from the national to the local. Third, its adjustment to the new urban governance rationales. Such transformations produce new forms of visibility for what emerges as a generalized acceptance of the plurality of belongings within a social imaginary presided over by the idea of diversity. This is built according to a specific framework that we seek to characterize in this text, where the new logics of urban development, the role of culture and the centrality of local space stand out.
\end{abstract}

Keywords: Interculturalism. Multiculturalism. Europeanization. Urban Governance. Recognition. 


\section{Introdução}

Atualmente, é discernível uma aguda crise do multiculturalismo como modelo de incorporação da diversidade cultural; e isto apesar da sistemática polissemia do conceito ou falta de uniformidade nas suas aplicações políticas. A crise provém fundamentalmente de o mesmo estar sendo desalojado por um conceito concorrente: o de interculturalismo. Não apenas ocupa este progressivamente o mesmo campo discursivo, como emerge como sendo a solução para os defeitos do multiculturalismo, pretendendo através da aplicação de novos princípios superá-los, e por esse mesmo passo, impor-se como novo modelo de regulação da diversidade cultural etnoracial. É, por conseguinte, nesta transição que pretendemos situar a discussão, perguntando se e quais as modificações nas formas sociais se apresentam como relevantes na crise do multiculturalismo. Concentrar a reflexão nas formas sociais indica desde logo que não intentamos percorrer os caminhos da filosofia política, onde o debate se encontra geralmente ancorado, bem assim como na sua focalização normativa e prescritiva. Antes, sugerimos que a transição deve ser analisada quanto aos seus aspectos práticos, as suas inscrições sociopolíticas, a sua difusão segundo ordens de ação social emergentes. Não significa que a definição de conceitos como multiculturalismo ou interculturalismo não seja ainda assim relevante. De forma que dedicamos a primeira parte do texto a discuti-los, a avaliar aproximações e distanciamentos; mas tendo sempre presente que a comparação não deve ficar pelo território teórico na medida em que estes são termos investidos política e socialmente. Quer isto dizer, que a pretendida relação de superação entre um e o outro só poderá ser compreendida quando lida à luz de uma evolução dos sentidos políticos e estratégicos que lhe são atribuídos. Julgamos que a Europa é um bom contexto onde analisar esse investimento. Primeiro, porque as instituições da EU e a europeização das suas políticas adotaram o interculturalismo como seu modelo oficial de incorporação da diversidade, como teremos oportunidade de mostrar. Segundo porque o fizeram segundo pressupostos bem específicos que permitem definir um conteúdo prático para além das confrontações teóricas. No entanto, este texto é eminentemente teórico, e se bem que acolha alguns exemplos como capacidade demonstrativa do argumento, consiste essencialmente num conjunto de reflexões, tidas por pertinentes para pensar a incorporação da diversidade cultural e étnica numa nova configuração globalizada, onde cultura e economia se entretecem de 
maneiras inovadoras e as práticas estruturantes são redimensionadas ao nível local (SASSEN, 1991).

Neste sentido, a nossa sugestão é que processos práticos se encontram em desenvolvimento cuja ancoragem empírica nos parece mais explicativa do que as diatribes normativas sobre o sentido último das sociedades plurais em termos culturais e étnico-raciais. Como referido atrás, começamos por um apanhado de algumas das teorias que balizam essa discussão tentando caracterizar termos como multiculturalismo e interculturalismo. Subsequentemente, debruçamo-nos sobre a adoção do interculturalismo como modelo europeu para concluirmos com uma proposta de compreensão da sua difusão consoante três ordens de fatores: a europeização do interculturalismo; o redimensionamento da integração dos imigrantes; a sua inserção nas atuais estratégias de governança urbana.

\section{Multiculturalismo: DOA (Death on Arrival)?}

Definindo multiculturalismo, seguindo Modood (2007, p. 2), como o reconhecimento de diferenças grupais em arenas públicas tais como a lei, políticas, discurso estatal, cidadania partilhada e identidade nacional, o que distingue este de simples políticas direcionadas para consolidação social da diversidade cultural é justamente a sua dimensão grupal; mais ainda, a sua dimensão comunitária como lógica de integração preponderante. Grande parte da confusão retórica que se instalou na academia provém desse fato. Por exemplo, Kymlicka, sem dúvida o maior defensor do multiculturalismo e da sua perpetuação no mundo ocidental, elabora um conjunto de oito indicadores que permitiriam perceber se o multiculturalismo ainda resiste ou não (BANTING e KYMLICKA, 2006). A conclusão é no mínimo surpreendente. Apesar de toda a retórica e desvinculação política contra o multiculturalismo, apesar do aumento exponencial do apoio de partidos populistas e de extrema-direita em tantos Estados europeus, os autores insistem que aquilo que se convencionou chamar de integração cívica incorpora na verdade diversas camadas de orientações multiculturais. Na mesma direção vão Meer e Modood (2012) para quem o que se tornou significativo não foi $o$ declínio do multiculturalismo, mas a sua surpreendente persistência. 
Aparentemente, o conceito de multiculturalismo tornou-se de tal forma elástico que políticas de acomodação da diversidade cultural, seja de que natureza for, são imediatamente arroladas ao seu escopo. Por esse fato, as 8 dimensões que Banting e Kymlicka (2006) elencam como sendo indicativas de multiculturalismo podem ser encontradas, em menor ou maior extensão, em praticamente todos os países ocidentais sem que estas inscrevam nas suas instituições uma dimensão explicitamente grupal.

Com efeito, quando nos debruçamos sobre contextos concretos no cenário europeu constatamos que termos como minorias étnicas, direitos grupais ou política de identidade têm paulatinamente sido desmobilizados ou desapareceram por completo do léxico político e institucional. Esta é uma situação contrastante com a América Latina, contexto no qual Mara Loveman (2014) identifica uma mudança ideológica dominante baseada no reconhecimento de claras demarcações étnico-raciais. Este contraste certificaria que o multiculturalismo se encontra em crise em alguns contextos regionais, tais como o europeu, mas não noutros.

No aspecto político-legal, a distinção entre multiculturalismo fraco e forte (SHACHAR, 2004, p. 28-29) ${ }^{2}$ tem respaldado a maioria dos entendimentos da incorporação da diversidade cultural no contexto do Estado-nação. Para Shachar (2004, p.28), a modalidade forte "obriga a uma redefinição fundamental das nossas noções de cidadania". Desde logo, porque as identidades dos grupos passam a ser extensamente refletidas no domínio legal, formal e constitucional para que estas possam governar os seus membros de acordo com as suas próprias regras. A relação com o Estado passa a diferenciar o laço de cidadania republicana abrindo este a formas específicas de autogoverno e à inclusão oficial das "vozes" dos grupos identitários no quadro constitucional e no discurso público. As formas fracas de multiculturalismo prendem-se com o equilíbrio entre acomodação de grupos identitários sem negligenciar os direitos do indivíduo. Kymlicka (1995) tem sido um dos principais proponentes desta visão. Através da noção de direitos das minorias, o autor estabelece claramente que estes direitos só podem ser incorporados quando não contradizem nem os

\footnotetext{
${ }^{2}$ Ver GRILLO, 2005 para uma caracterização mais sociológica desta dicotomia.
} 
direitos humanos, nem os princípios democráticos, de liberdade individual e justiça social.

Num outro modo de equacionar o tema, existem duas linhas distintas enquanto formas de pensar o multiculturalismo: uma linha dialógica que encontramos em Parekh (2000) e a importância que este devota ao diálogo cultural assim como Taylor (1994); e uma linha procedimentalista que encontramos em Kymlicka (1995) e a centralidade que este atribui às regras e direitos. Podemos dizer que muito embora ambas se alicercem na teoria política liberal, escolhem caminhos diversos. De um lado Kymlicka (1995) e a visão de uma sociedade multicultural onde os direitos das culturas minoritárias sejam garantidos e protegidos; do outro, a dialogia parekhiana implicando uma quase proposta ontológica, ou seja, a diversidade é um valor em si mesmo porque através do contraste com as outras culturas é o nosso ser social, como eminentemente cultural, que é percebido e isso amplifica a nossa própria compreensão da diversidade humana e do que é ser-se humano.

Modood (2007) é ainda assim continuador desta linha ao propor que o multiculturalismo deve ser entendido enquanto extensão do liberalismo tradicional. Essa extensão não reflete mais do que o igualitarismo liberal, numa terceira versão normativa, ou seja, após consideração de uma primeira e segunda geração de normas correspondentes à liberdade e igualdade respectivamente, surge uma terceira geração de legitimação das diferenças culturais razoáveis (TULLY, 2002, p. 102). Ora esta terceira geração possui implicações na definição de cidadania e na sua extensão, pressupondo agora o reconhecimento não apenas de indivíduos, mas também de grupos como parte objetiva da vida social. Note-se contudo que as causas de uma amplificação da cidadania de natureza multicultural devem ser diferenciadas regionalmente. Não pretendendo ser exaustivo, enquanto os desafios multiculturais se apresentam na Europa como resultado da imigração pós-colonial, na América-latina, por exemplo, as reflexões e práticas políticas referemse sobretudo aos povos indígenas e mais recentemente à população negra. Não sendo o foco deste texto examinar estas diferenças, convirá, no entanto, salientar que enquanto a segunda carreia uma agenda emancipatória de empoderamento das populações subalternizadas, os desafios europeus prendem-se com a expansão da cidadania para os imigrantes e os seus reflexos nas concepções nacionais de pertença 
perante o "estrangeiro". Significa que embora os temas possam ser em certa medida transversais, os objetos de reflexão são, contudo, diversos. Esquematicamente, enquanto o paradigma latino-americano se liga a uma agenda antirracista e, nas palavras de Gross (2012), de re-etnização, o modelo Europeu prende-se com políticas de acomodação da diversidade originada pelos fluxos migratórios pós-coloniais.

Não obstante estas particularidades geográficas, a definição de multiculturalismo pode ser minimal consistindo meramente na adoção por parte do Estado de políticas que promovam ativamente a diversidade (STRATON e ANG, 1998). Neste sentido, toda a iniciativa que for em substância contrária a uma tendência homogeneizadora do Estado-nação seria por definição multicultural. Uma tal definição corre o risco de negligenciar o jogo político que envolve as ambivalências do multiculturalismo, tais como o seu uso na retórica política cuja expressão europeia tem evidenciado essencialmente um pendor crítico. Compreender que a polissemia inerente ao termo multiculturalismo é estrategicamente negociada no campo político significa atentar que este não é apenas um termo contestado teoricamente, é também uma referência polemizada no jogo do poder classificatório, ou seja, de atribuições de legitimação ou de censura pelos usos dominantes da linguagem (BOURDIEU, 1979).

Apesar de uma crise generalizada do modelo multiculturalista assumida e propalada pelas forças políticas e estatais, uma constelação de autores continua a insistir que aquilo que os Estados fazem é ainda assim multiculturalismo (MODOOD e MEER, 2012; BANTING e KYMLICKA, 2006; KOOPMANS, 2013). Interpretações sustentadas em índices multiculturais que comparam os países de acordo com a extensão das políticas de diversidade insistem que se trata de um fenômeno mais disseminado do que os críticos estão preparados para admitir. Koopmans (2013) defende a necessidade de distinguir "conceitos de segunda ordem" das formulações sustentadas pelos autores no intuito de ganhar alguma distância analítica. Este quadro nomotético esbarra no entanto contra evidências que parecem difíceis de superar. A despeito das potencialidades heurísticas de tais instrumentos, podemos, com efeito, começar por levantar uma questão bastante direta: para que serve classificar o modelo holandês como multiculturalista (KOOPMANS et al., 2005) se nesse mesmo contexto, mais do que em qualquer outro, uma reação extremada contra o 
multiculturalismo tem sido patente (SHOLTEN, 2013; PRINS e SAHARS, 2010; ENTZINGER, 2006)?

Jeffrey Alexander (2013) caracterizou este fenômeno de reação extrema contra o multiculturalismo na Europa nas suas duas vertentes de estreitamento dos canais de recrutamento de imigrantes (as políticas de entrada) e intensificação dos mecanismos de assimilação (medidas mais restritivas para conceder a nacionalidade). Em virtude destas políticas, o panorama traçado é de declínio das taxas de naturalização e de obtenção de cidadania de maneira generalizada no espaço europeu (GOODMAN 2011; 2012). O que se tornou crítico de acordo com esta análise foi a intensificação da cidadania cívica, ou seja, dos elos de pertença aos respectivos Estados-nação e da exigência de competências básicas que os imigrantes devem ter para provarem essa ligação (testes de nacionalidade, competências linguísticas, etc). Este tem sido interpretado como um teste ao próprio multiculturalismo. Todavia, é justo observar que esta exigência é segmentada não tendo os mesmos impactos sobre os imigrantes nem sendo independente da proveniência destes. Com efeito, sistemas recentemente implementados como os "vistos gold" permitem exercer esta pressão de adesão cívica de forma seletiva e controlada. Para estes, as obrigações ao nível das competências ou da demonstração de adesão aos núcleos culturais e cívicos dos estados de acolhimento não se colocam.

É neste sentido que as comparações de modelos nacionais que adotam conceitos como multicultural ou assimilacionista não fazem mais do que proceder a um fechamento epistêmico que acaba por ser utilizado pelos próprios políticos como forma de classificar a sua ação. Só assim se pode compreender uma reação extremada contra o multiculturalismo por parte de governantes e decisores políticos, quando toda a evidência aponta para que tal modelo nunca tenha existido na Europa, nem no presumível prototípico país multicultural, a Inglaterra (JOPPKE, 1999).

Uma tal constatação tem levado cada vez mais autores a questionarem se a retórica anti-multiculturalismo não é no fundo uma construção neoliberal (LENTIN e TILEY, 2011; COOPER, 2004; KUNDNANI, 2007; ZIZEK, 1997). Segundo esta interpretação, a consonância com que tais acusações foram endereçadas ao multiculturalismo - no espaço de seis meses Merkel, Sarkozy e Cameron pronunciaram-se publicamente contra o mesmo - encobre um programa mais abrangente 
de reestruturação do coletivo nacional que pressupõe, por um lado, uma convergência de interesses e valores nos limites cívicos da nação - um núcleo de adesão mínima; por outro, uma evacuação dos conteúdos políticos emancipatórios em favor de uma culturalização das relações humanas. O que nos permite em última análise falar de pósmulticulturalismo como uma configuração específica da linguagem política, do papel do Estado, e dos agentes envolvidos em novos mecanismos de coordenação da ação. É justamente isso que as propostas interculturalistas parecem salientar como teremos ocasião de analisar abaixo.

\section{Interculturalismo(s): novas polissemias.}

A um nível teórico o interculturalismo tem assumido um estatuto de paradigma alternativo ao multiculturalismo (BOUCHARD, 2011). O debate recente entre defensores do multiculturalismo (MEER e MODOOD, 2012) e defensores do interculturalismo (CANTLE, 2012; ZAPATA-BARRERO, 2015), mostra que o segundo tem vindo a ocupar uma posição proeminente no mesmo campo discursivo. Outrora exclusivamente ocupado pelo debate em torno do multiculturalismo, com ramificações no comunitarismo de pendor mais liberal (KYMLICKA,1995; MODOOD, 2007) ou mais crítico (YOUNG, 1990; BENHABIB, 1992), a discussão sobre a coesão social das sociedades de imigração passou a ser igualmente reivindicada por um novo modelo intercultural.

Das críticas endossadas ao multiculturalismo há pelo menos duas que têm obtido uma ressonância pública e académica muito significativa: primeiro, o multiculturalismo cria realidades culturais estanques que não comunicam entre si, impedindo assim a partilha através dos canais cívicos que estruturam as nossas sociedades ocidentais; segundo, tal fato decorre fundamentalmente porque as identidades são definidas como elementos inamovíveis onde as pessoas são encaixadas segundo determinados atributos (CANTLE, 2012). A crítica a estas duas assunções tem passado por, primeiro, estender os canais cívicos que possam abrir os grupos à intercomunicação, insistindo que nenhuma cultura é estanque mas antes híbrida; segundo, visto que as identidades são relacionais, devemos falar antes de identificações, e modos 
diferenciados das pessoas escolherem entre pertenças que lhes são significativas.

Esta interpretação, contudo, está longe de ser consensual. Por exemplo, autores como Meer e Modood (2012) contestam as diferenças entre o multiculturalismo e o interculturalismo mostrando que são mais as aproximações do que os distanciamentos teóricos. Ao elencarem quatro aspectos fundamentais que distinguiriam o interculturalismo dos modelos precedentes, estes autores concluem que tais diferenças não possuem espessura teórica uma vez que o multiculturalismo já as contemplaria. Sobretudo, a insistência segundo a qual o interculturalismo seria mais orientado para o diálogo e interação é considerada deslocada na medida em que o multiculturalismo assim como equacionado por Taylor (1994) e Parekh (2000) confere ao diálogo uma importância fundamental (MEER e MODOOD, 2012, p. 183-184). Por conseguinte, as diferenças entre os dois modelos estariam a ser amplificadas e seriam mais os pontos de contato do que as irredutibilidades. A conclusão pareceria apontar não para o desmantelamento, mas para a surpreendente resistência do multiculturalismo.

No entanto, os deslizes retóricos que os termos têm sofrido possuem uma certa instrumentalidade política. Assim, o anátema caiu sobre a palavra "diferença", sendo substituída nos meios políticos e acadêmicos por "diversidade". É esta última que encontramos na maioria dos programas de integração de imigrantes nos países europeus. Declinada de diversas maneiras é certo, mas sempre com a mesma intenção: Vielfalt, na Alemanha; Interculturalidade, em Portugal; Diversité, em França; Diversitat, na Itália. Esta conjugação de significados sociais da diversidade não será seguramente alheia às intenções europeias de harmonização das políticas de integração e ao mecanismo imitativo que a própria estrutura da comitologia e da governance gera entre países, ou seja, a adoção não apenas das mesmas soluções políticas, mas também dos mesmos significados sociais e representações públicas dessas mesmas políticas. Esta disseminação do conceito de diversidade faz-se acompanhar de uma mudança concertada em algumas políticas, por isso não acontece apenas no domínio discursivo. Esta nova configuração assenta no binômio diversidade-interculturalidade como dois termos da organização social da diferença. Podemos inclusivamente dizer que se a 
diversidade surge como a representação do social a interculturalidade corresponde à sua formulação política e paradigmática.

Mas a própria interculturalidade possui sentidos diferenciados. Interculturalidade surge de maneira proeminente em Canclini (1995), como o movimento nas identidades dos grupos e dos indivíduos em direção a identidades híbridas e múltiplas, característica generalizada dos espaços urbanos globalizados. Ou numa perspectiva crítica e decolonial, como a que encontramos em Walsh (2010), para a qual o trabalho de descolonização passa por inverter as estruturas da "colonialidade do poder" questionando sistematicamente os processos de racialização, subalternização e inferiorização e os seus padrões de poder, legitimando diálogos e maneiras de ser da diferença num contexto social de igualdade. A mesma orientação é seguida por Santos (2003) para quem as formas mais emancipatórias que o multiculturalismo assume poderiam ser identificadas na crítica póscolonial, sendo que a política da diferença surgiria como uma extensão, igualmente emancipatória, das lutas canônicas da modernidade. Este multiculturalismo emancipatório, segundo a designação de Santos possui maiores afinidades com o interculturalismo crítico do que com o multiculturalismo de orientação liberal (KYMLICKA, 1995; MODOOD, 1997; TULLY, 2002; PAREKH, 2000). Se a primeira discussão coloca a ênfase naquilo que Modood designa por "a componente multicultural da política", a segunda abraça a problematização de como acomodar reivindicações culturais e étnicas na teoria política liberal. Este debate, fundamentalmente de pendor normativo como temos vindo a sublinhar, colide com o programa "crítico" com a sua ênfase na prática das lutas sociais. Aliás, o cerne do multiculturalismo radical nas suas origens norte-americanas era, como salientou Young (1990) colocar o foco nos efeitos do poder, da dominação, e da opressão histórica nas oportunidades políticas e pessoais daqueles que pertenciam às minorias e grupos étnicos. Esta é uma diferença de monta com as teorizações liberais. Todavia, é justamente este enfoque que se encontra em reversão nas novas políticas da diversidade, em particular o interculturalismo europeu.

Com efeito, Cantle (2012) define o interculturalismo como o modelo para a atual sociedade internacional. As suas premissas são o valor da interação entre culturas, abertura e diálogo, em contraste com conceções primordiais de cultura. Neste sentido, os indivíduos não são vinculados 
a culturas de pertença particulares. A ênfase é colocada na interação dos indivíduos entre diferentes comunidades étnicas e culturais (ALEXANDER, 2007). A abordagem intercultural está, segundo os seus apologistas, focada nas diferenças internas aos próprios grupos e não apenas entre os grupos, e nisso se distingue do multiculturalismo. Zapata-Barrero (2016) oferece uma abordagem teórica dos múltiplos significados do interculturalismo. Segundo ele, o interculturalismo pode assumir três formas correspondentes a três vertentes da diversidade. A contratual, que coloca a ênfase nos valores tradicionais de uma nação e na capacidade destes serem partilhados pelos seus cidadãos. Neste caso, a afiliação dos cidadãos para com as estruturas básicas da sociedade é assegurada através do equilíbrio entre lealdades e direitos dos imigrantes (ZAPATA-BARRERO, 2016, p. 159). A coesiva, que envolve a transformação de zonas potencialmente conflituais em zonas de contato positivo. E a construtiva, apostada na promoção das capacidades culturais dos indivíduos e na ligação entre bens e recursos culturais necessários ao desenvolvimento de práticas criativas e inovadoras. Para Zapata-Barrero, o interculturalismo deve articular as três vertentes da tradição, coesão e inovação. A tradição, a que ZapataBarrero faz corresponder a vertente política da diversidade, corresponde latu senso à assimilação, i.e., a capacidade dos imigrantes no encontro com a sociedade de acolhimento modificarem as suas práticas e identidades de formas consentâneas à tradição nativa enquanto os valores sociais centrais são preservados. Da mesma forma, diríamos que o eixo da coesão estaria associado a uma proposta de natureza comunicacional, sobretudo no que tange à definição de espaços de encontro e à redução de conflitos potenciais entre adesões culturais diferenciadas. De certo modo, o núcleo dialógico das teorias do reconhecimento, como defendido por Parekh (2000) e Taylor (1994), já contemplariam esta vertente, embora de forma mais aprofundada como visto atrás. Resta a parte da inovação e desenvolvimento. Esta parece constituir verdadeiramente o núcleo da nova proposta intercultural. A linguagem adotada coincide com o programa da diversity advantage assim como equacionado por Wood e Landry (2008). Esta abordagem funde os estudos urbanos com a gestão da diversidade entendendo a diversidade como um recurso que deve ser associado à nova economia simbólica e ao desenvolvimento urbano. Seguindo estes pressupostos, é esta articulação que surge consequente na aplicação da lógica intercultural. Tendo por certo que a interação ocupa um lugar privilegiado no seio deste paradigma, a sua versão desenvolvimentista 
(ou construtiva, se seguirmos Zapata-Barrero) quadra com a ideia de diversidade enquanto "bem público", recurso a ser gerido.

\section{As ideias estruturantes do interculturalismo prático}

A ideia segundo a qual as classificações legítimas inscrevem a sua realidade nas "instituições instituídas", como diria Bourdieu, deve ser considerada quando atendemos à disseminação europeia da linguagem e práticas classificadas politicamente como interculturais. De tal forma que devemos investigar o interculturalismo como o modo europeu de incorporação da diversidade, ou como quer Faist (2009) da heterogeneidade.

Com efeito, o interculturalismo parece ter-se tornado a linguagem institucional normativa disseminada mundialmente: o Banco Mundial, o Conselho da Europa ou a Comissão Europeia são algumas das instâncias internacionais que "falam" a linguagem do interculturalismo (CANTLE, 2012). A assunção de um modelo intercultural por parte da Europa possui as suas consequências práticas e políticas, que vão bem para além das discussões de filosofia política e as suas polêmicas normativistas. Gostaríamos de propor que elas se inscrevem em três ordens de fatores. Primeiro, a europeização do modelo, ou seja, a disseminação dos mesmos scripts pelas instituições imprimindo modos de fazer idênticos e uniformizadores. Segundo, o redimensionamento da escala do espaço de integração dos imigrantes do nacional para o local. Terceiro, o seu ajustamento às novas lógicas de governança urbana. Cada um destes fatores possui um efeito reforçador e contribui para a consolidação de um modelo cuja expressão política se definiu como de “diversity advantage". Compreender que a diversity advantage é a nova retórica da incorporação da diferença permite perspectivar melhor como os dilemas multiculturais anteriores estão sendo assimilados numa nova linguagem e prática. Possibilita igualmente sair do impasse a que o pensamento sobre modelos de incorporação nos leva. A maior evidência de um tal impasse é Modood chegar à conclusão que "o sentido último do multiculturalismo" é acomodar todos os outros modelos, negligenciando que a carga política com que estes modelos são afetados 
não se joga num território neutro, mas antes numa sucessão de encadeamentos que extravasa em muito o pluralismo cultural ${ }^{3}$.

\section{Europeização do interculturalismo}

A despeito dos trabalhos referidos anteriormente que certificam a permanência das estratégias multiculturais em vários países, as instituições europeias assumiram o modelo intercultural como o seu modelo de incorporação da diversidade cultural ${ }^{4}$. Nos Princípios Básicos Comuns (PBCs) para a Integração definidos no Conselho da União Europeia de 19 de novembro de 2004 a interação entre nacionais e imigrantes é considerada fundamental para uma integração bemsucedida. E logo no Princípio Comum $n^{\circ} 7$ afirma-se o diálogo intercultural como estratégia para "estimular" essas interações 5 . Posteriormente, o White Paper on Intercultural Dialogue do Conselho da Europa formula a questão do interculturalismo como a prática social resultante de uma governança da diversidade de natureza democrática. Nesta medida, afirma a interculturalidade como o melhor modelo de governança da diversidade porque "previne cisões étnicas, religiosas, linguísticas e culturais" e aposta na "promoção da compreensão mútua" permitindo assumir "construtiva e democraticamente as nossas

\footnotetext{
${ }^{3}$ É assim que por exemplo Marine Le Pen da Front National francesa pode reivindicar uma França para os franceses associando simultaneamente a ideia de uma reforma do Estado-providência e de como deve este ser exclusivo dos cidadãos nacionais. Da mesma forma, a retórica antissistema de Le Pen ataca fundamentalmente os imigrantes e o pluralismo religioso. Ou seja, a politização da imigração não se joga apenas no campo de uma pressuposta incompatibilidade de valores - impossibilidade de aceitação da diferença - mas como num processo de encadeamentos que atingem as noções de Estado, justiça, redistribuição e solidariedade (ver por exemplo, BEHRENT,2017).

${ }^{4}$ As premissas básicas do modelo foram de fato disseminadas e integradas nas agendas políticas dos diversos países, mesmo que com traduções práticas diferentes, com especial relevo para a sua incorporação nas orientações de política migratória dos países da União Europeia.

${ }^{5}$ CBP 7 'Frequent interaction between immigrants and Member State citizens is a fundamental mechanism for integration. Shared forums, intercultural dialogue, education about immigrants and immigrant cultures, and stimulating living conditions in urban environments enhance the interactions between immigrants and Member State citizens'.
} 
identidades diferenciadas com base em valores universais partilhados (White paper on Intercultural Dialogue, 2008). Por conseguinte, existe uma conexão lógica bastante evidente entre a linguagem da diversidade e a interculturalidade como fazendo ambas parte da mesma forma de governança.

A disseminação de termos nucleares da estratégia e legislação europeias bem assim como das medidas que os sustentam tem o nome de europeização (RADAELLI, 2000; FLIGSTEIN, 2001; VINK, 2003). Quando nos reportamos às imigrações existe uma vasta teorização sobre este processo (GUIRAUDON, 2003) que embora apontando variações nas tendências europeizadoras, tais como a extensão e penetração das mesmas, apoia a ideia de uma generalização dos modelos e políticas emitidas a nível europeu e adotados pelos Estados-membros. Este modelo possui determinados vetores que importa elucidar e que constituem os alicerces para a implementação dessas políticas.

Primeiro, estabelece a necessidade de considerar um redimensionamento do espaço da integração. Esta necessidade acompanha outras redefinições, sobretudo no campo acadêmico, onde podemos identificar um movimento do espaço nacional para o local. Tal tendência tem conduzido a uma reavaliação do multiculturalismo ao mesmo tempo que resgata o espaço e as políticas locais permitindo identificar outras abordagens à diversidade (VERTOVEC, 2007; GLICK SCHILLER, 2015). Por outro lado, o próprio sistema de subsidiariedade da $\mathrm{UE}^{6}$ implica que este redimensionamento seja efetuado na medida em que as cidades possuem maior competência para gerir o princípio da proximidade. As primeiras referências a uma tal deslocação surgem na Common Agenda for Integration - Framework for the Integration of Third-Country Nationals in the European Union, de 2005, onde se afirma que "a integração tem lugar no espaço local, como parte da vida quotidiana"7. A referência ao espaço local será reforçada em 2011, como parte da revisão dessa mesma agenda, onde se enuncia que "a integração é um processo que tem lugar antes de tudo ao nível local. As interações (...) entre imigrantes e outros residentes ao nível do

\footnotetext{
${ }^{6} \mathrm{O}$ princípio da subsidiariedade dita que se exclua a intervenção da União quando uma matéria pode ser regulamentada de modo eficaz pelos Estados-Membros a nível central, regional ou local.

${ }^{7}$ Tradução do autor: "integration takes place at the local level as part of daily life" (p.15).
} 
bairro são elementos fundamentais da integração"8. A importância do local é amplamente sublinhada pela ideia de cidade intercultural que preside ao Programa Intercultural Cities do Conselho da Europa. Esta concepção é indicada pelo seu mentor Phil Wood quando se refere que "um dos fatores que determinarão quais as cidades que florescerão e quais declinarão será a forma como permitirão que a diversidade seja o seu recurso, ou a sua desvantagem" (COUNCIL OF EUROPE, 2009, p. 22).

Segundo, esboça-se uma linha muito concreta entre desenvolvimento da economia urbana e diversidade cultural trazida pelos fluxos imigrantes. Esta relação, porém, faz-se consoante parâmetros específicos devedores de novas lógicas de governança e desenvolvimento urbano. A forma como os imigrantes e os seus traços culturais são incorporados nestas novas lógicas é própria do interculturalismo na sua modalidade "consumista"9. Com efeito, estas são indissociáveis dos processos de reinvenção da cidade típicos da nova economia cultural e simbólica. Por conseguinte, as práticas associadas a novas lógicas deixaram de ser enquadradas num discurso de justiça - como era o multiculturalismo para entrarem como elementos reconhecíveis nos processos de reestruturação urbana das cidades globalizadas. A eleição do local como espaço de integração faz depender, em última análise, essa eleição das próprias potencialidades de um determinado local. Por conseguinte, é impossível pensar qualquer atual modelo de reconhecimento da diferença ou da heterogeneidade social e cultural sem que este contemple as profundas transformações da organização da economia e governança urbanas. Neste sentido, estamos perante um novo modelo de reconhecimento que designamos de "reconhecimento pela performance", o qual caracterizamos em seguida.

\footnotetext{
${ }^{8}$ Tradução do autor: "Integration is a process that takes place primarily at the local level. The interactions and exchanges between immigrants and other residents at neighbourhood level are key elements of integration" [Com 2011 455, p. 17, European Agenda for the Integration of Third-Country Nationals].

9 Preferimos classificar esta modalidade de "consumista" ao invés de

"construtivista". As razões para o fazer são identificadas na seção seguinte.
} 


\section{Governança urbana e regimes de visibilidade}

Quando Charles Taylor (1994) elaborou o seu pensamento sobre o reconhecimento, fê-lo de uma forma quase axiomática: a nossa identidade é formada pelo reconhecimento ou pela ausência deste; se este reconhecimento for distorcido, esta identidade sofre danos reais. Após esta posição, o debate balizou-se sobre questões ontológicas, sobre a viabilidade de uma identidade grupal, o potencial reificador que a noção de reconhecimento encerra, ou a essencialização do grupo e consequente esmagamento do indivíduo (BENHABIB, 2007; PHILLIPS, 2007; YOUNG, 2000). Aqui não é o sítio para discutir a teoria do reconhecimento e as suas múltiplas análises. Associar o reconhecimento à visibilidade é algo a que a própria teoria do reconhecimento não é alheia. Brighenti (2007) estabelece a ligação ao propor a noção de campo de visibilidade enquanto conjunto de interrelações estratégicas que tornam os elementos (pessoas e objetos) mais ou menos visíveis. É um campo investido de normatividade e poder na medida em que estabelece relações assimétricas que tornam a visibilidade um produto de mercado. Existe assim a boa visibilidade e a má; a infraexposição e a sobre-exposição. A visibilidade é uma característica dos espaços urbanos e tem sido uma categoria fundamental da organização destes espaços durante toda a modernidade ocidental (SENNETT, 1997). Com efeito, entre a divisão de espaços públicos e privados há todo um conjunto de mediações que se interpõem produtoras de visibilidade ou de invisibilidade. É neste sentido que a questão da visibilidade das minorias no espaço público deve ser equacionada com as modalidades sociais de produzir essa mesma visibilidade. A despeito das sistemáticas operações de etnicização por parte da sociedade de acolhimento decorrentes quer da segregação quer das operações de "marcação" associadas a práticas em contextos determinados, a visibilidade étnica é, atualmente e em complemento, explorada por mecanismos globais integrados nas lógicas do mercado e da estetização da cultura. Se esta visibilidade era apanhada pelo discurso da diferença e estigmatização, argumentamos que passou a ser captada por outros sistemas e processos que não apenas os da exclusão ou racialização - desde logo porque o etnicamente visível é procurado e instigado ao invés de se pretender a sua invisibilização. Ou pelo menos esta é a forma social com que estas pertenças integram os novos processos de organização social da cidade globalizada. É justamente quanto ao campo de visibilidade que as modificações nesta inflexão 
política são, quanto a nós, mais assinaláveis. Por outras palavras, contrariamente à ideia recorrente segundo a qual a visibilidade das minorias étnicas gera sentimentos de rejeição e exclusão, outros modelos e estratégias de visibilização tornaram-se operativos. Quando os críticos de pendor antirracista falam de marcadores étnicos colocam geralmente o pressuposto negativo da visibilidade. Ora a visibilidade do étnico é atualmente intensamente explorada quando associada a processos de reestruturação da cidade globalizada capitalista. Esta é uma visibilidade controlada segundo parâmetros associados à culturalização do desenvolvimento urbano. Este novo modelo, que podemos designar como oferecendo uma lente diferente que permite o reconhecimento, mas doutra natureza, apesar da sua normatividade intrínseca, porque estabelece lugares sociais assimétricos e entendidos como tal, não é prescritivo como as anteriores teorias do reconhecimento. Com efeito, esta forma social é performativa e nesse sentido podemos falar de reconhecimento pela performance.

Como temos visto, argumentamos que este modelo só pode ser compreendido na perspetiva dum movimento de "localização" em conjunção com novas estratégias de governança urbana. Ele deve ser entendido em relação a três fatores que se reforçam e combinam no sentido de produzir a nova visibilidade. Primeiro, este modelo de reconhecimento ao deixar de ter um carácter prescritivo significa que deixou de contemplar "as injustiças do falso reconhecimento"10 (FRASER, 2005) para explorar essencialmente o seu caráter de espetacularidade. Brighenti (2008) numa reformulação dos tipos de reconhecimento de Honneth propõe uma nova esfera, a da espetacularidade. Esta é uma esfera essencialmente performativa.

Segundo, os novos modelos de governança urbana possuem uma particular incidência na revitalização dos centros (históricos) das cidades, associados a uma retórica da cosmopolitização e a processos de promoção da cultura enquanto alavancas essenciais para a economia do conhecimento e da criatividade (FLORIDA, 2005; WOOD e LANDRY, 2008). É neste sentido que a cultura enquanto recurso se apresenta com uma expressão difusa que vai desde formas eruditas até ao exótico e

\footnotetext{
${ }^{10}$ A expressão injustices of misrecognition é referente ao domínio político, segundo Fraser (2005). Este domínio estabelece as fronteiras de quem está incluído ou excluído da prerrogativa de uma justa distribuição e reconhecimento recíproco.
} 
diferente das manifestações culturais imigrantes. No "estágio estético do consumo" (LIPOVETSKY; SERROY, 2013, p.329) a importância desloca-se para a fruição sensitiva e estética que faz parte da reinvenção do espaço urbano enquanto associação do consumismo com a estética mercantil. Terceiro, a importância do empreendedorismo imigrante (ou étnico) para esta revitalização é assumida nas políticas de renovação dos centros; a ela se associa uma preocupação com a criatividade e atratividade destes espaços que constitui uma nova equação da governança urbana. Esta conjugação surge de forma muito nítida em diversas instâncias cujos exemplos aqui apenas oferecemos alguns. Vemo-la surgir na estratégia de Lisboa para 2020, interligando as duas dimensões da interculturalidade e o crescimento urbano.

[...] valorizar o interculturalismo e promover a cidadania e melhorar o funcionamento da cidade. Estas áreas são fundamentais para o poder de atração da cidade para os residentes e as empresas, tornando Lisboa uma boa cidade para viver, trabalhar e visitar (CML, 2012, p. 24).

Do mesmo modo, o plano para a integração da cidade de Dublin, na Irlanda afirma que

[...] a diversidade humana é reconhecida como significativa na promoção da qualidade de vida urbana necessária para atrair e reter trabalhadores e firmas na economia do conhecimento, a criação da experiência do visitante que promove a economia turística, e impulsiona o empreendedorismo e criatividade (DUBLIN CITY COUNCIL, 2008, p. 8).

E ainda, a cidade de Viena apresenta a sua diversidade como uma vantagem comparativa na atração de pessoas com talento e de investimento $^{11}$. As três lógicas articuladas - inovação, empreendedorismo, criatividade - traduzem uma compreensão dos fluxos migratórios já não como força de trabalho, mas como capital humano. É como capital humano que o imigrante é incorporado na nova governança urbana. $\mathrm{O}$ interculturalismo prático surge assim não tanto como um modelo de acomodação escorado na teorização política, mas como uma forma prática de reconhecimento da diferença cultural em cenários de capitalismo culturalizado e estetizado. Formas como a

\footnotetext{
${ }^{11}$ STEP 2025, Urban Development Plan Vienna.
} 
festivalização da diversidade, a exibição culinária ou a participação das culturas minoritárias na publicitação e marketização do espaço, são algumas das características deste novo empreendimento social. Por exemplo, em Lisboa a Junta de Freguesia de Arroios utiliza a imagem de uma área intercultural no centro da cidade como parte da sua estratégia de comunicação e marketing. Explorando a diferença específica de uma área habitacional que compreende 92 nacionalidades, a identidade de Arroios foi recentemente construída tendo por base esta imagética cosmopolita.

Sugerir a europeização deste modelo não significa que seja este exclusivo do contexto europeu. Com efeito, tais dinâmicas podem ser encontradas nos mais diversos contextos. A cidade de Buenos Aires possui um programa de celebração das diversas nacionalidades que ali se encontram e vivem que concede um dos espaços mais emblemáticos da cidade - em contiguidade com a Plaza de Mayo - às associações de imigrantes para aí exporem e comercializarem os seus produtos "étnicos"12. Contudo, a Europa parece ter elevado o conceito ao estatuto de política e as suas organizações foram porventura as que melhor articularam essas práticas com um modelo geral de integração dos imigrantes.

Neste processo o espaço ganha uma dimensão simbólica de primeira ordem. A diversidade enquanto "imagem da diversidade" integra os discursos e práticas dos agentes públicos e privados apostados na reconstrução das formas como os espaços são percebidos (OLIVEIRA; PADILLA, 2017). Ou seja, a diversidade cultural, nos espaços centrais das cidades passou a ser um elemento crucial na transformação do mindscape urbano. Bianchini (2006) define urban mindscape como "o banco de imagens urbano que inclui imagens locais e externas da cidade" (p.15). A ideia de um espaço cuja autenticidade reside na sua interculturalidade é captada nestas estratégias que organizam as representações da cidade, em particular dos seus centros. A diferença entre os centros e as periferias não deve ser negligenciada. A diversidade cultural das periferias, geralmente dos grandes aglomerados urbanos, nas coroas citadinas, em situações de maior concentração e escassez

\footnotetext{
${ }^{12}$ Buenos Aires Celebra, disponível em: http://www.buenosaires.gob.ar/derechoshumanos/colectividades/buenosairescelebra. Acesso em 21 jun.-2017.
} 
econômica, não suscita este cruzamento entre estratégias de marketização, embelezamento dos lugares e retórica inclusiva. Neste preciso sentido, a dinâmica de reconhecimento que assiste à conjuntura brevemente caracterizada é ela própria segmentada, incluindo alguns e excluindo tantos outros.

\section{Conclusão}

Procuramos neste artigo argumentar que as questões associadas ao interculturalismo devem ser perspectivadas não apenas quanto ao domínio normativo, próprio das teorizações filosóficas, mas quanto à sua dimensão prática. Neste sentido, a defesa da superação do multiculturalismo por um novo paradigma intercultural deve ser lida não apenas relativamente às aproximações ou distanciamentos teóricos, mas naquilo que ela encerra de político e social. A este respeito, procuramos caracterizar uma mudança que quanto a nós se afigura fundamental nas lógicas de reconhecimento e visibilização das minorias étnicas e culturais. É essa que para nós constitui a principal modificação trazida pelo interculturalismo. A adesão por parte dos agentes europeus a um tal modelo deve ser entendida como tendo por pano de fundo aquilo que ele representa na prática, ou seja, nas modificações dos sistemas de ordenação social da diferença. Novos mecanismos conceituais e estratégicos integram agora as expressões culturais minoritárias dentro de um regime diverso de reconhecimento. Culturalização da economia, empreendedorismo urbano, governança local são os novos contextos sociopolíticos através dos quais a questão da diferença cultural decorrente da imigração deve ser perspectivada. Sem prejuízo de outras formas de representação menos benignas tais como sentimentos antiimigração explorados pela extrema-direita, islamofobia ou racismo, este quadro emergente imprime a sua ordem aos processos (autorizados) de construção da diferença e da alteridade. A apologia da diversidade cultural foi de fato captada por outros discursos e práticas; formulações arredadas da politização anterior que acompanhava as lutas antirracistas e os movimentos de política de identidade. Neste novo regime é o diverso pela sua própria natureza de diversificado (passe o pleonasmo) que é cultivado, apresentado e representado. Esta formatação torna-se tanto mais eficaz quanto maior for a sua associação a processos de 
culturalização do urbano, de marketização do espaço e de cosmopolitização da vida social.

\section{Referências}

ALEXANDER, J. Struggling over the mode of incorporation: backlash against multiculturalism in Europe. Ethnic and Racial Studies, v. 36, n. $4, \quad$ p. $\quad 531-556, \quad 2013$. http://dx.doi.org/10.1080/01419870.2012.752515.

ALEXANDER, M. Cities and Labour Immigration: Comparing Policy Responses in Amsterdam, Paris, Rome and Tel Aviv. Aldershot: Ashgate, 2007.

BOUCHARD, G. What is Interculturalism? McGill Law Journal, v. 56, n. 2, p. 435-468, 2011.

BANTING, K. e KYMLICKA, W. Introduction: Multiculturalism and the welfare state: Setting the context. In: Banting, K.; Kymlicka, W. (Ed.), Multiculturalism and the Welfare State. Recognition and redistribution in contemporary democracies. Oxford: Oxford University Press, 2006.

BENHABIB, S. Situating the Self: Gender, Community and Postmodernism in Contemporary Ethics. Nova Iorque: Routledge, 1992.

Democratic Exclusions and Democratic Iterations : Dilemmas of «Just Membership » and Prospects of cosmopolitan federalism. European Journal of Political Theory, v. 6, n. 4 p. 445-462, 2007.

BEHRENT, M. C. Twilight of the political? On the ideological disarray of French politics. Modern and Contemporary France, v. 25, n. 1, p. 75-81, 2017.

BIANCHINI, F. Introduction. European Urban Mindscapes: Concepts, Cultural Representations and Policy Applications. In: WEISSSUSSEX, G.; BIANCHINI, F. (Ed.) Urban Mindscapes of Europe. European Studies, 23, Amsterdam: Editions Rodopi, 2006.

BRIGHENTI, A. M. Visibility. A category for the social sciences. Current Sociology, v. 55, n.3, p.323-342, 2007. 
Etnografia e ricerca qualitativa, 1/2008, Visuale, visible, etnográfico. Etnografia e Ricerca Qualitativa, v. 1, n. 1, p. 91-113, 2008.

CANCLINI, N. G. Hibrid Cultures. Strategies for entering and leaving modernity. Mineappolis: University of Minesota Press, 1995.

CANTLE, T. Interculturalism. The New Era of Cohesion and Diversity. Houndmills: Palgrave Macmillan, 2012.

COOPER, D. Challenging Diversity: Rethinking Equality and the Value of Difference. Cambridge: Cambridge University Press, 2004.

COUNCIL OF EUROPE. Living Together As Equals in Dignity, White Paper on Intercultural Dialogue. Strasbourg: Council of Europe2008. Intercultural Cities: Towards a model for intercultural integration, edited by Phil Wood, Strasbourg, 2009.

ENTZINGER, H. "The parallel decline of multiculturalism and the welfare state in the Netherlands. In: BANTING, M.; KYMLICKA, W. (Ed.) Multiculturalism and the Welfare State: Recognition and redistribution in contemporary democracies. Oxford: Oxford University Press, p.177-201, 2006.

ESTRATÉGIA LX2020 - Lisboa no quadro do próximo período de programação comunitário, CML, novembro 2012.

EUROPEAN COMMISSION, A Common Agenda for Integration Framework for the Integration of Third-Country Nationals in the European Union [COM/2005/0389 final], Brussels: Commission of the European Communities, 2005.

FAIST, T. Diversity - a new mode of incorporation? Ethnic and Racial Studies, v. 32, n. 1, p. 171-190, 2009, DOI: 10.1080/01419870802483650.

FLIGSTEIN, N. The process of Europeanization. Politique européenne 1/2000, $\mathrm{n}^{\circ} 1$, p. 25-42, 2000.

FLORIDA, R. Cities and the Creative Class. Nova Iorque: Routledge, 2005.

FRASER, N. Abnormal justice. In: APPIAH, K. A.; BENHABIB, S.; YOUNG, I. M., FRASER, N. (Ed.), Justice, Governance, 
Cosmopolitanism, and the Politics of Difference. Berlim: Humboldt Universitat, p. 117-147, 2005.

GLICK SCHILLER, N. Diasporic cosmopolitanism, migrants, sociabilities, and city-making. In: GLICK SCHILLER, N.; IRVING, A. (Ed.) Whose cosmopolitanism? Critical Perspective, relationalities and discontents. Nova Iorque: Bergan Press, p. 103-120, 2015.

GOODMAN, S. W. Fortifying citizenship: policy strategies for civic integration in Western Europe. World Politics, v. 674, n. 4, p. 659-98, 2011.

Integration requirements for integration's sake? Identifying, categorizing and comparing civil integration policies. Journal of Ethnic and Migration Studies, v. 36, n. 5, p. 753 72, 2012.

GRILLO, R. Backlash against diversity? Identities and cultural politics in European Cities. Compas Working Paper 14, University of Oxford, 2005.

GROSS, C. Políticas de la Etnicidad. Identidad, Estado y Modernidad. Bogotá: Instituto Colombiano de Antropologia y História, 2012.

GUIRAUDON, V. L'européanisation des politiques publiques de migration. In: ALIGISAKIS M. (dir.) L'Europe face à l'autre: politiques migratoires et intégration européenne. Genéve: Publications Europa, p. 32- 52, 2003.

KUNDNANI, A. The end of tolerance: Racism in 21st century Britain. London: Pluto Press, 2007.

LENTIN, A.; TILEY, G. The crisis of multiculturalism: racism in a neoliberal age. London: Zed books, 2011.

LIPOVETSKY, G.; SERROY, J. L'esthétisation du monde. Vivre à l'âge du capitalisme artiste. Paris, Editions Gallimard, 2013.

KOOPMANS, R. Multiculturalism and Immigration. A Contested Field in Cross National Comparison. Annual Review of Sociology, v. 39, p.147-69, 2013.

KOOPMANS, R. et alii. Contested Citizenship. Immigration and Cultural Diversity in Europe. Minneapolis; London: University of Minnesota Press, 2005. 
KYMLICKA, W. Multicultural Citizenship: A Liberal Theory of Minority Rights. Oxford: Oxford University Press, 1995.

LOVEMAN, M. National Colors: Racial Classification and the State in Latin America. Nova Iorque: Oxford University Press, 2014.

MEER, N. ; MODOOD, T. How does Interculturalism contrast with Multiculturalism? Journal of Intercultural Studies, v. 33, n.2, pp: 175-197, 2012.

MODOOD, T. Multiculturalism. A Civic Idea. Cambridge: Polity Press, 2007.

OLIVEIRA, N; PADILLA, B. Integrating superdiversity in local governance. The case of Lisbon's inner-city. Policy and Politics, 2017. doi.org/10.1332/030557317X14835601760639 [fast track].

PAREKH, B. Rethinking Multiculturalism: Cultural Diversity and Political Theory. Basingstoke: Macmillan Press/Palgrave, 2000.

PHILLIPS, A. Multiculturalism without culture. Princeton, NJ: Princeton University Press, 2007.

PRINS, B.; SAHARS, S. From toleration to repression: the Dutch backlash against Multiculturalism. In: VERTOVEC, S.; WESSENDORF, S. (Ed.) The Multiculturalism Backlash. European Discourses, Policies and Practices. Londres: Routledge, p.72-91, 2010.

RADAELLI, C. M. Whither europeanization? Concept stretching and substantive change. European Integration online Papers (EIoP) v..4, n. 8, 2000. Disponível em http://eiop.or.at/eiop/texte/2000-008a.htm.

SANTOS, B. S. Reconhecer para libertar. Os caminhos do cosmopolitismo multicultural. Rio de Janeiro: Civilização Brasileira, 2003.

SASSEN, S. The Global City: New York, London, Tokyo. Princeton: Princeton University Press, 1991.

SENNETT, R. El cuerpo y la ciudad. Madrid: Alianza Editorial, 1997.

SHACHAR, A. Multicultural Jurisdictions. Cambridge: CUP, 2004. 
SHOLTEN, P. The Dutch Multicultural Myth. In: TARAS, Raymond (Ed.) Challenging Multiculturalism. European Models of Diversity. Edinburgh: Edinburgh University Press, p. 97-119, 2013.

STEP 2025, Urban Development Plan Vienna, Urban Department, 2014.

TAYLOR, C. The Politics of Recognition. In: GUTMANN, Amy (Ed.) Multiculturalism: Examining the Politics of Recognition, Princeton, NJ: Princeton University Press, p.25-73, 1994.

Towards Integration. A city framework. Dublin City Council, 2008.

TULLY, J. The illiberal liberal. Brian Barry's political attack on multiculturalism. In: P. Kelly (Ed.) Multiculturalism reconsidered. Cambridge: Polity, pp. 102-113, 2002.

VERTOVEC, S. Super-diversity and its implications. Ethnic and Racial Studies, v. 30, n. 6, p. 1024-1054, 2007.

VINK, M. What is europeanisation? And other questions on a new research agenda". European Political Science, v. 3, n. 1, p. 63-74, 2003.

YOUNG, I. M. Justice and the Politics of Difference. Princeton: Princeton University Press, 1990.

WALSH, C. Interculturalidad Crítica y Educación Intercultural. In: VIAÑA, J.; TAPIA, L.; WALSH, C. (Org.) Construyendo Interculturalidad Crítica. La Paz: Instituto Internacional de Integración del Convenio Andrés Bello, p. 75-96, 2010.

WOOD, P.; LANDRY, C. The Intercultural City. Planning for Diversity Advantage. London: Earthscan, 2008.

ZAPATA-BARRERO, R. Exploring the foundations of the intercultural policy paradigm: a comprehensive approach. Identities, v. 23; n. 2, p. 155-173, 2016. DOI: 10.1080/1070289X.2015.1006523

ZIZEK, S. Multiculturalism, or, the cultural logic of multinational capitalism. New Left Review I/225 Sept.-Oct., p. 28-51, 1997. 